\title{
ChemProspector and generic structures: advanced mining and searching of chemical content
}

\author{
Valentina Eigner-Pitto*, Josef Eiblmaier, Hans Kraut, Larisa Isenko, Heinz Saller, Peter Loew \\ From 7th German Conference on Chemoinformatics: 25 CIC-Workshop \\ Goslar, Germany. 6-8 November 2011
}

Chemical information mining has turned into a well-established scientific area over the last five years. Several software solutions exist that are able to identify and extract names of chemical compounds in text documents and convert them into chemical structure-searchable information. Likewise, several programs exist which recognize chemical structures from images and translate them into the computer-readable format, the connection table. However, a still unsolved issue is the automatic abstraction of generic compounds (Markush structures). These usually consist of a core structure image and variable groups specified in the text, in additional images or in tables.

This presentation describes our hybrid approach to extract generic structure information from documents by using combining information science, cheminformatics, computational linguistics and pattern recognition techniques. Experiences with the envisaged methodology and the first results are presented.

This research project is funded by the German Ministry of Economics and Technology. It is part of the THESEUS research programme which has the goal to facilitate access to information, combine data to form new kinds of knowledge and lay the groundwork for new services on the Internet.

Published: 1 May 2012

doi:10.1186/1758-2946-4-S1-017

Cite this article as: Eigner-Pitto et al:: ChemProspector and generic structures: advanced mining and searching of chemical content. Journal of Cheminformatics 2012 4(Suppl 1):017.

* Correspondence: ve@infochem.de InfoChem GmbH, München, 81241, Germany
Publish with ChemistryCentral and every scientist can read your work free of charge

"Open access provides opportunities to our colleagues in other parts of the globe, by allowing anyone to view the content free of charge."

W. Jeffery Hurst, The Hershey Company.

- available free of charge to the entire scientific community

- peer reviewed and published immediately upon acceptance

- cited in PubMed and archived on PubMed Central

- yours - you keep the copyright

Submit your manuscript here:

http://www.chemistrycentral.com/manuscript/

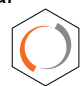

ChemistryCentral 